\title{
Identification of aerobic heterotrophic bacteria from the photic zone of a hypersaline microbial mat
}

\author{
Henk M. Jonkers*, Raeid M. M. Abed \\ Max Planck Institute for Marine Microbiology, Celsiusstrasse 1, 28359 Bremen, Germany
}

\begin{abstract}
Aerobic heterotrophic bacteria inhabiting microbial mats play an important role in carbon-cycling, yet information about their identity is scarce. We used the most probable number technique combined with denaturing gradient gel electrophoresis (DGGE) to identify apparent numerically important populations of aerobic heterotrophic bacteria in a hypersaline microbial mat. At high dilutions, populations related to the genera Rhodobacter and Roseobacter and to the genera Marinobacter and Halomonas dominated glycolate and yeast extract-amended enrichment cultures respectively. Three selected isolates of aerobic heterotrophic bacteria were obtained from glycolateamended enrichments and found to relate phylogenetically to species of the genus Roseobacter. These strains were found to grow, in addition to glycolate, on several other photosynthetic compounds known to be produced by cyanobacteria suggesting that they specialize in mineralizing photosynthetic excretion products. Our study demonstrates that aerobic heterotrophs, which are phylogenetically affiliated to genera such as Rhodobacter, Roseobacter, Marinobacter and Halomonas, are important in hypersaline microbial mats, and that their specific in situ role in the carbon cycle needs to be further investigated.
\end{abstract}

KEY WORDS: Photosynthate-using bacteria $\cdot$ Microbial mat $\cdot$ Phylogeny $\cdot$ DGGE Resale or republication not permitted without written consent of the publisher

\section{INTRODUCTION}

Microbial mats are ideal model ecosystems for studying carbon-cycling, as they are inhabited by a wide variety of metabolically different functional groups of microorganisms. They develop particularly well in marine as well as extreme environments such as hot springs (Bateson \& Ward 1988), intertidal sediments (Bauld 1984, DeWit et al. 1989) and hypersaline lakes (Jørgensen \& Cohen 1977). In illuminated mats, cyanobacteria and diatoms are often the dominant primary producers. Their photosynthetic activity results in oxygen super-saturation during the day, while at night anoxic conditions prevail due to continued activity of heterotrophic microorganisms (Jørgensen et al. 1983, VanGemerden 1993, Wieland \& Kühl 2000). The pho-

*Email: hjonkers@mpi-bremen.de totrophs are considered to be the driving force of the system because they provide other community members with organic substrates (Stal 1995). Aerobic heterotrophic and sulfate-reducing bacteria are expected to play a major role in organic carbon mineralization in the photic zone of such mats, due to the changing diurnal oxic and anoxic conditions. Although sulfatereducing bacteria are relatively well studied in hypersaline microbial mats (Caumette et al. 1991, Wawer \& Muyzer 1995, Krekeler et al. 1997, Teske et al. 1998, Minz et al. 1999a,b), virtually nothing is known about the identity and specific role of aerobic heterotrophic bacteria. In this study, therefore, we report on the phylogenetic identification of apparent dominant populations of aerobic heterotrophs in a hypersaline microbial mat by combining cultivation and molecular techniques. Isolated strains were also obtained and checked for their potential to utilize a range of organic substrates. 


\section{MATERIALS AND METHODS}

Microbial mat, sample handling and medium composition. A hypersaline microbial mat, growing in an outdoor experimental pond at the Interuniversity Institute of Eilat, Israel, was chosen as the study objective. The pond was inoculated in 1996 with mats originating from Solar Lake (Sinai, Egypt). Since then a stable multi-layered mat has developed, which has been maintained under concentrated Red Sea water with a salinity of $9 \%$. The photic zone, as previously established with microsensor techniques (Minz et al. 1999a,b), comprised the top $2 \mathrm{~mm}$ of the mat and contained various species of diatoms, and unicellular and filamentous cyanobacteria (Abed \& Garcia-Pichel 2001). In April 1999, triplicate cores (25 mm diameter) were randomly taken from the mat. The top $2 \mathrm{~mm}$ of these cores were pooled, fragmented by cutting and then suspended in 9 volumes of medium. This suspension was homogenized by shaking at maximum speed for $5 \mathrm{~min}$ on a Vortex mixer. Glycolate- and yeast extract-using bacteria were specifically enriched by the following procedure: the bacterial suspension was 10 -fold diluted in 8 parallel series up to the $10^{-11}$ dilution level in $8 \times 12$ well micro-titer plates that contained hypersaline medium. The last row of 8 wells was not inoculated and served as an abiotic control. Glycolate $(20 \mathrm{mM})$ or yeast extract $\left(1.3 \mathrm{mg} \mathrm{l}^{-1}\right.$, corresponding to about $40 \mathrm{mM}$ organic carbon) were added as substrates. Plates were aerobically incubated for $8 \mathrm{wk}$ at $28^{\circ} \mathrm{C}$ and illuminated under dim fluorescent light $\left(20 \mu \mathrm{mol}\right.$ photons $\left.\mathrm{m}^{-2} \mathrm{~s}^{-1}\right)$ in order not to exclude growth of aerobic phototrophic bacteria.

The hypersaline mineral medium composition was (in $\mathrm{g} \mathrm{l}^{-1}$ ): $\mathrm{NaCl}$ (90.0), $\mathrm{Na}_{2} \mathrm{CO}_{3}$ (2.0), $\mathrm{NH}_{4} \mathrm{Cl}$ (0.2), $\mathrm{KH}_{2} \mathrm{PO}_{4}$ (0.02), $\mathrm{CaCl}_{2} \cdot 2 \mathrm{H}_{2} \mathrm{O}$ (0.225), $\mathrm{KCl}(0.2), \mathrm{MgCl}_{2}$. $6 \mathrm{H}_{2} \mathrm{O}(0.2)$, EDTA-trace element solution of Widdel \& Bak (1992) (1 ml $\left.\mathrm{l}^{-1}\right)$, vitamin solution of Heijthuijsen \& Hansen (1986) (1 $\left.\mathrm{ml} \mathrm{l}^{-1}\right)$. The $\mathrm{pH}$ of the medium was adjusted to 8.2.

Community composition analysis by DGGE in serial diluted mat suspension. Community analysis of cultures, after enrichment on glycolate or yeast-extract of serial diluted microbial mat suspensions, was done by denaturing gradient gel electrophoresis (DGGE). This process facilitates the determination of the genetic diversity of complex microbial populations. After PCR amplification, partial 16S rRNA genes are separated on a denaturing gradient gel (Muyzer et al. 1993, Muyzer \& Smalla 1998). Growth occurred up to the $10^{-7}$ dilution level of both glycolate and yeast-extractincubated enrichment cultures from serial diluted mat suspensions. Therefore, for DGGE analysis, $0.2 \mathrm{ml}$ samples were taken from cultures up to the $10^{-8}$ dilution level, the latter serving as negative control.
Culture aliquots were centrifuged followed by resuspension of the pellet in $30 \mu \mathrm{l}$ TE buffer (10 mM Tris$\mathrm{HCl}, 1$ mM EDTA; pH 8). DNA was extracted by subjecting cell suspensions to 5 cycles of freezing (liquid nitrogen) and thawing at $65^{\circ} \mathrm{C}$, followed by heating for $10 \mathrm{~min}$ at $95^{\circ} \mathrm{C}$. Mixtures of $16 \mathrm{~S}$ rRNA genes in these samples were PCR-amplified with GM5 forward (with GC clamp) and 907 reverse primers (Muyzer et al. 1995). Subsequently, DGGE was performed as described by Muyzer et al. (1995). DGGE bands from the lowest $\left(10^{-2}\right)$ and highest positive $\left(10^{-6}\right.$ and $\left.10^{-7}\right)$ dilutions were excised from the gel, reamplified by PCR and reanalyzed by DGGE to ensure purity before sequencing. Sequencing of PCR products was done commercially.

Isolation and characterization of isolates. Pure cultures of glycolate-using isolates were obtained by inoculation of agar plates with microbial mat suspensions, followed by repeated plating of obtained colonies. Agar mineral medium consisted of hypersaline mineral medium augmented with $20 \mathrm{~g} \mathrm{l}^{-1}$ agar and $20 \mathrm{mM}$ glycolate. After growth, 2 different types of colonies could be distinguished on agar plates: numerically dominant white colonies and smaller transparent colonies. Ten colonies, 5 of each type, were also subjected to DGGE analysis in order to check for variability. In addition, substrate utilization spectra of selected isolates (strains Gl1 and Gl2, both white colony types, and Gl3, transparent colony type) were determined. Gene sequences of nearly the complete 16S rRNA gene of these isolates were analyzed after PCR amplification of genomic DNA from $200 \mu \mathrm{l}$ culture aliquots using the PCR primers GM3F and GM4R (Muyzer et al. 1995).

Substrate utilization spectra of isolates were determined in batch culture. Individual substrates (see Table 1) were added to the hypersaline medium to a final concentration of $10 \mathrm{mM}$ and tubes were inoculated with $100 \mu \mathrm{l}$ aliquots of cultures pre-grown on glycolate. Growth in independent duplicate cultures was measured by following changes in optical density at $660 \mathrm{~nm}$ (OD660) against biotic (no substrate added) and sterile (no bacteria added) controls. The relationship between substrate use (measured as change in dissolved organic carbon concentration), OD660, and protein production was determined in a control experiment in which strain GL2 was grown in batch culture with 20 mM glycolate as growth substrate.

Potential photopigment production of strains Gl1, Gl2 and Gl3 was determined by measuring absorption spectra of living cells with a Perkin Elmer Lambda 20 spectrophotometer after suspension of dense cultures (40 mg protein $\mathrm{l}^{-1}$ ) in sucrose, according to Pfennig \& Trüper (1992).

Phylogenetic analyses. The partial 16S rRNA gene sequences of the DGGE bands and the almost full 
sequences of the isolates were analyzed using the ARB software package (Ludwig et al. 1998). A phylogenetic tree (maximum likelihood) was constructed based on long 16S rRNA sequences (more than 1300 base pairs) of predominantly cultivated strains, available from the ARB database by applying different methods integrated in the ARB software. Sequences obtained in this study were aligned to the sequences in the ARB database using the alignment tool of the ARB software package. The long sequences of the isolates were included in the tree calculations, whereas the partial sequences of the DGGE phylotypes were inserted into the pre-established tree using the parsimony ARB tool, maintaining the overall tree topology without changes.

Table 1. Substrate spectra of aerobic heterotrophic strains Gl1, Gl2 and Gl3 that were isolated from an experimental hypersaline microbial mat. -: no growth (within $28 \mathrm{~d}$ of incubation); \pm : slow growth (within $28 \mathrm{~d}$ of incubation); +: growth (maximum reached within $10 \mathrm{~d}$ of incubation); ++: fast growth (maximum reached within $3 \mathrm{~d}$ of incubation)

\begin{tabular}{|c|c|c|c|}
\hline Substrate (10 mM) & Strain Gl1 & Strain Gl2 & Strain Gl3 \\
\hline Thiosulfate & - & - & - \\
\hline DMSO & - & - & - \\
\hline DMA & - & - & - \\
\hline TMA & - & - & - \\
\hline Formic acid ${ }^{a, b}$ & - & - & - \\
\hline Methanol & \pm & \pm & - \\
\hline Ethanol $^{\mathrm{b}}$ & + & + & - \\
\hline Acetic acid ${ }^{a, b}$ & ++ & ++ & + \\
\hline Glycolic acid ${ }^{\mathrm{a}}$ & + & ++ & \pm \\
\hline Glyoxyalic acid $^{\mathrm{a}}$ & + & + & 0 \\
\hline Glycerol $^{\mathrm{a}}$ & + & + & + \\
\hline Propanol & + & \pm & 0 \\
\hline 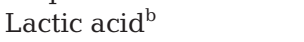 & ++ & + & ++ \\
\hline Propionic acid & ++ & + & ++ \\
\hline Acrylic acid & ++ & + & 0 \\
\hline Pyruvic acid ${ }^{\mathrm{a}}$ & ++ & + & ++ \\
\hline Malic acid & ++ & + & ++ \\
\hline Fumaric acid ${ }^{\mathrm{a}}$ & ++ & + & ++ \\
\hline Succinic acid ${ }^{\mathrm{a}}$ & ++ & + & ++ \\
\hline Methylsuccinic acid ${ }^{\mathrm{a}}$ & + & \pm & 0 \\
\hline n-butyric acid & \pm & \pm & \pm \\
\hline$\beta$-hydroxybutyric acid ${ }^{a}$ & ++ & + & 0 \\
\hline Betain $^{c}$ & ++ & + & 0 \\
\hline iso-valeric acid ${ }^{\mathrm{a}}$ & + & + & 0 \\
\hline$\alpha$-ketoglutaric acid & ++ & + & + \\
\hline Proline & 0 & 0 & + \\
\hline Citric ccid $^{\mathrm{a}}$ & 0 & 0 & 0 \\
\hline Glucose & 0 & 0 & ++ \\
\hline \multicolumn{4}{|c|}{$\begin{array}{l}\text { a'Identified as excretion product of Synechoccocus strains } \\
\text { (Teiser 1993) } \\
\text { bIdentified as fermentation product of cyanobacteria } \\
\text { (Stal 1995) } \\
\text { 'Identified as cyanobacterial compatible solute } \\
\text { (Galinski 1995) }\end{array}$} \\
\hline
\end{tabular}

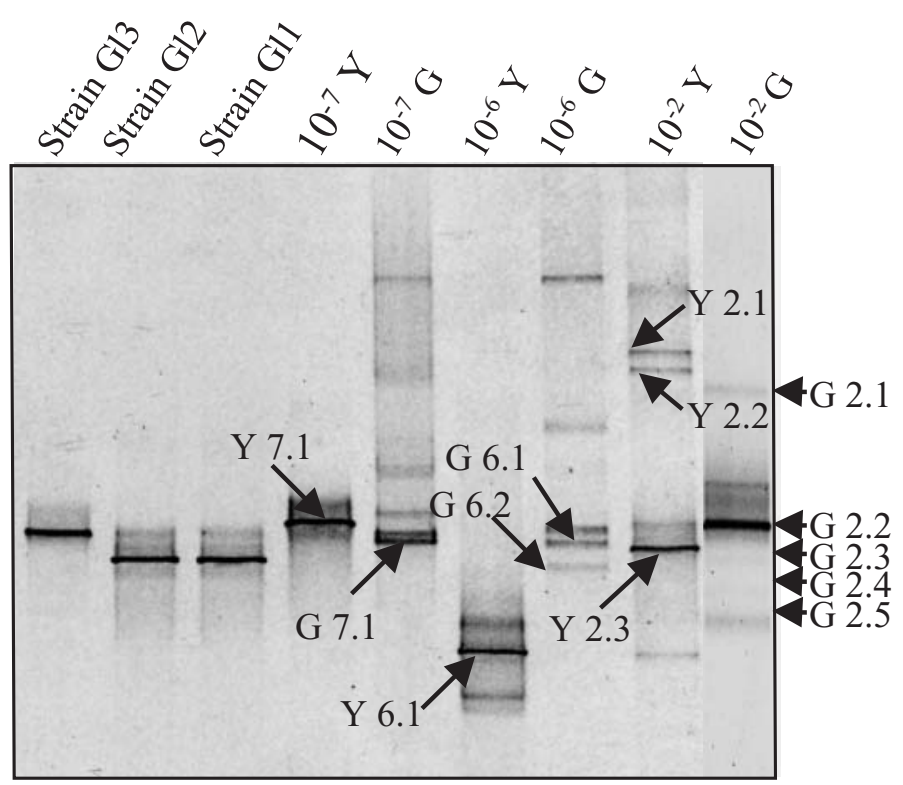

Fig. 1. Negative image of DGGE separation patterns of PCRamplified 16S rRNA gene fragments from serial diluted microbial mat suspensions after enrichment on glycolate (G) or yeast extract $(\mathrm{Y})$. Respective dilution level shown above each lane. Arrows and codes correspond to excised bands which were successfully re-amplified and sequenced

Analytical procedures. Production of formic acid in cultures of strain Gl2 growing on glycolate was confirmed qualitatively by measuring formic acid and glycolic acid by HPLC after derivatization with 2nitrophenylhydrazine according to the method of Albert \& Martens (1997).

Dissolved organic and inorganic carbon concentrations in culture supernatant were determined with a Shimadzu TOC-5050A total organic carbon analyzer connected to a Shimadzu ASI-5000A auto sampler. Hypersaline samples were 5-fold diluted with Milli-Q water prior to analysis. Protein in culture extracts was measured according to Bradford (1976).

\section{RESULTS}

\section{DGGE analysis of enrichment cultures and phylogeny of isolates}

Growth of bacteria in individual microtiter plate wells could be easily visualized due to turbidity changes. Growth was observed in the $10^{-2}$ up to the $10^{-7}$ dilution level of both the glycolate and yeast extract incubations. The number of bands which appeared on the DGGE gel from the lowest $\left(10^{-2}\right)$ to the highest $\left(10^{-7}\right)$ positive dilution level decreased both in the glycolate and yeast extract incubated series (Fig. 1). In addition to the number of bands, the posi- 


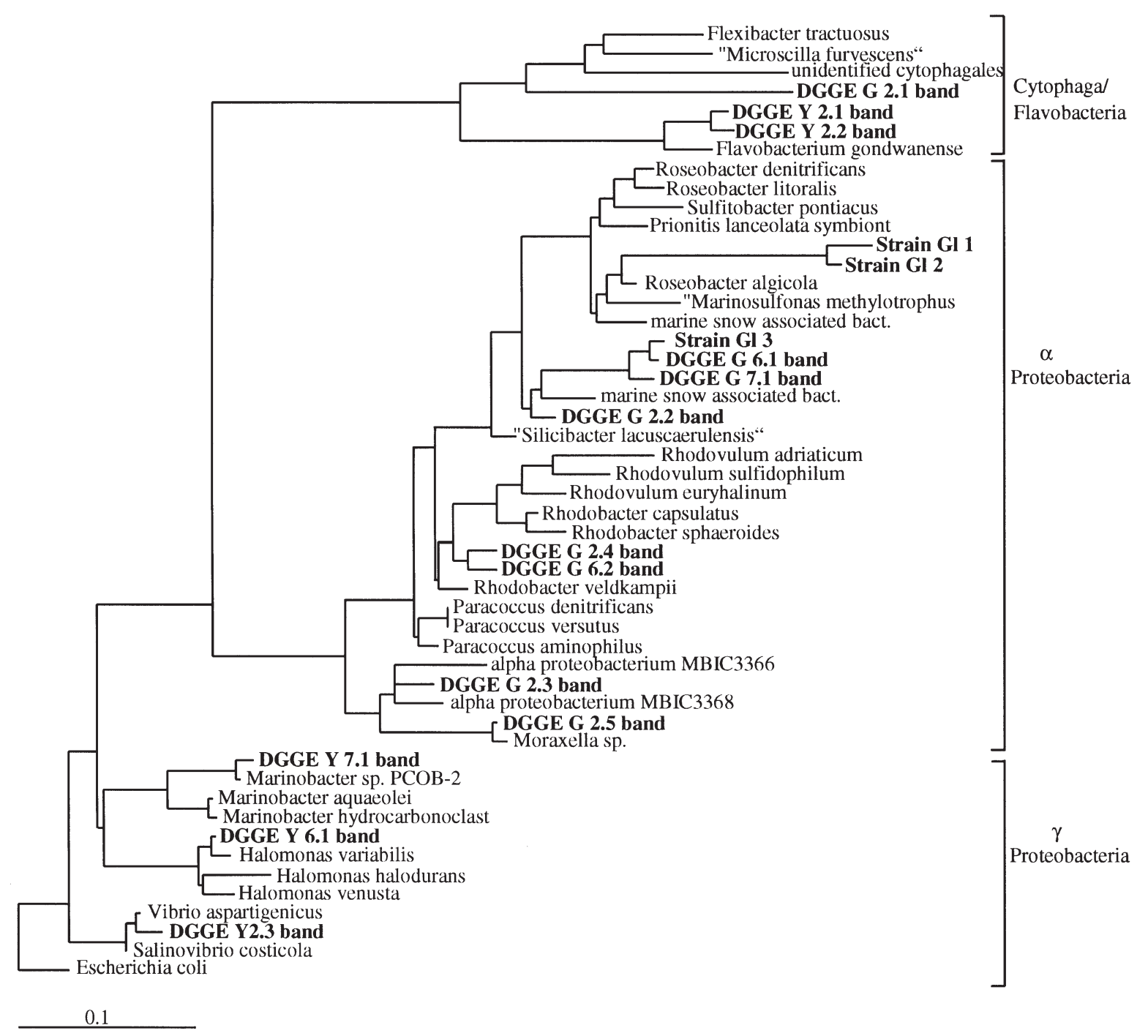

Fig. 2. Maximum likelihood phylogenetic tree showing placement of 16S rRNA gene sequences of glycolate-degrading isolates and DGGE bands from glycolate and yeast extract enrichments (see Fig. 1)

tion of bands also changed. Several bands present in the lower dilutions were replaced by others in higher dilution levels. Moreover, positions of DGGE bands from the glycolate incubations were different from those of the yeast extract incubations, indicating that respective phylotypes were phylogenetically different.

Sequences of excised DGGE bands from the lowest $\left(10^{-2}\right)$ and highest $\left(10^{-6}\right.$ and $\left.10^{-7}\right)$ dilution levels (indicated by arrows and band numbers in Fig. 1) revealed that DGGE phylotypes of the glycolate incubated series were primarily affiliated with members of the $\alpha$-subclass of the Proteobacteria. One exception was DGGE band G 2.1. It originated from the lowest dilution level and grouped with the Cytophaga/Flavobacterium cluster (Fig. 2). The DGGE phylotypes of the yeast-extract-incubated series, Y 6.1 and 7.1, originating from the higher dilution levels $10^{-6}$ and $10^{-7}$, grouped specifically with members of the $\gamma$-subclass of the Proteobacteria, with species of the genera Marinobacter and Halomonas. The DGGE phylotypes Y 2.1 and 2.2, which originated from the lowest dilution level $10^{-2}$, grouped with the Cytophaga/Flavobacterium cluster, while the most prominent band Y 2.3 grouped again within the $\gamma$-subclass of the Proteobacteria. The glycolate-using isolates Strain Gl1, Strain Gl2 and Strain Gl3 were also found to be affiliated with members of the $\alpha$-Proteobacteria. In fact, Strain Gl3 was found to be closely related to DGGE phylotypes G 6.1 and G 7.2 since these formed a specific subcluster within the $\alpha$-Proteobacteria. Strain Gl3 shared a similarity of $91 \%$ with Roseobacter denitrificans and $92 \%$ 


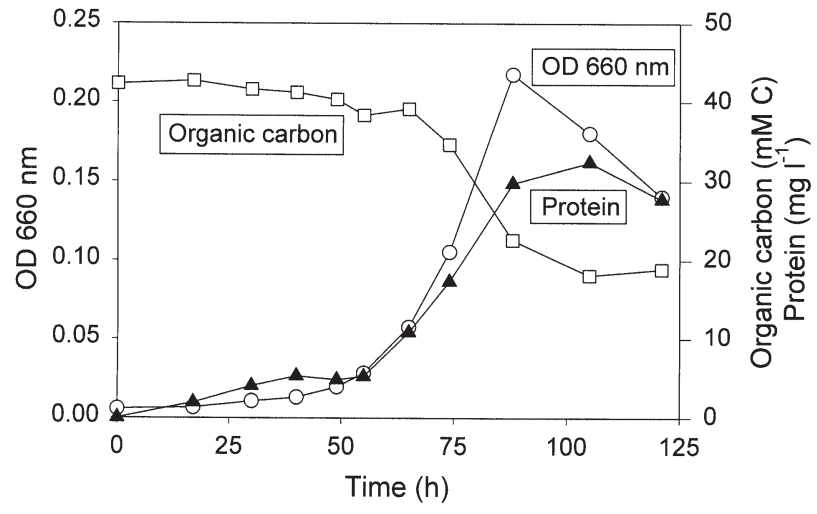

Fig. 3. Growth of isolate Gl2 on glycolate $(20 \mathrm{mM})$ in batch culture. Glycolate degradation was determined by measuring decrease in extracellular organic carbon content of culture. HPLC analysis revealed that formate was produced during growth on glycolate. OD: optical density

with Sulfitobacter pontiacus, Roseobacter litoralis and a gall symbiont of Prionitis lanceolata (see Fig. 2). Strains Gl1 and Gl2 showed a high sequence similarity $(98 \%)$ and formed a specific subcluster within the $\alpha$-Proteobacteria. They were phylogenetically affiliated with several species of the genus Roseobacter, although the sequence similarity with their nearest relative Roseobacter algicola was only $93 \%$.

\section{Substrate utilization by glycolate-using isolates}

The strains Gl1, Gl2 and Gl3 that were isolated on glycolate were able to grow on a variety of substrates (Table 1). Strains Gl1 and Gl2 showed identical substrate utilization patterns, while that of Strain Gl3 was different. The former strains grew well on several alcohols and some short chain fatty acids (glyoxalic and acrylic acid) while Strain Gl3 showed little or no growth on these compounds. All strains grew well on C3 fatty acids (propionic, lactic and pyruvic acid) and C4 fatty acids (malic, fumaric and succinic acid). $\beta$-hydroxybutyric acid, however, could not be used by Strain Gl3, while all strains grew well on the citricacid-cycle intermediate $\alpha$-ketoglutaric acid. Notable differences were the inability of Strain Gl3 to grow on the compatible solute betain, while Strains Gl1 and Gl2 showed no growth on proline or glucose. HPLC analysis of culture medium during growth revealed that Strains G11 and G12 oxidized the tested alcohols to their respective fatty acids prior to further degradation. Formic acid was detected as a degradation product of organic substrates in all strains, but this compound did not support growth in any strain when provided as a sole substrate. Furthermore, cul- tures rapidly disintegrated after reaching maximum optical density (Fig. 3).

Spectrophotometric analysis of cell suspensions in sucrose of Strains Gl1, Gl2 and Gl3 revealed that $\mathrm{BChl} a$ or other photopigments were not produced in detectable amounts by these organisms when cultured under aerobic conditions.

\section{DISCUSSION}

Populations of aerobic heterotrophic bacteria affiliated to members of the genera Rhodobacter, Roseobacter, Marinobacter and Halomonas dominated enrichments of high-dilution mat suspensions, and thus represented numerically important populations. In contrast, populations affiliated to the Cytophaga/ Flavobacterium cluster were found to be less abundant in the mat as they only dominated the lower dilutions. The latter populations dominated the former populations probably as a result of their superior growth rate, whereas at higher dilution, they were diluted to extinction. However, by using a cultivation step we might have failed to recover dominant populations that resist cultivation (Amann et al. 1995). In our study, a cultivation-based enrichment step was unavoidable in order to distinguish aerobic heterotrophs from other functional groups. On the other hand, the advantage of the enrichment procedure was that it enabled us to assess some of the physiological capabilities of the obtained populations.

DGGE analysis revealed that glycolate, a relatively simple substrate, yielded in the higher dilutions a community composition of aerobic heterotrophic bacteria that was, as expected, different from yeast extract enrichments. However, the obtained species diversity with yeast extract, a complex substrate mixture, was lower than in glycolate enrichments. This probably means that, to get a full view of the biodiversity within a functional group, one should not use a complex substrate mixture but instead a series of individual substrates in distinct enrichments. Fig. 1 shows that glycolate enrichments of high-diluted inocula yielded several distinct populations that we were able to identify as being related to Rhodobacter and Roseobacter genera. One would expect that instead of several populations, only the 1 with the best specific substrate affinity would have dominated such a single-substrate enrichment. This can be explained by secondary substrate production. As was shown in the pure culture studies, the isolated Roseobacter-affiliated strains produced formate during growth on glycolate, and this secondary substrate probably supported growth of the Rhodobacter-affiliated populations in the glycolate enrichments. This phenomenon not only explains why 
a single substrate may support growth of several populations in enrichment cultures, but also clarifies why Rhodobacter-affiliated strains were not obtained during strain purification with glycolate as substrate. On the other hand, it was surprising that DGGE analysis of yeast extract enrichments did not reveal a much higher diversity in higher dilutions because of the complex substrate composition. We hypothesize that the Marinobacter- and Halomonas-affiliated strains that dominated the enrichments of the higher dilutions represent populations with a broad substrate spectrum, and thus were able to overgrow substrate specialists, i.e. populations with much narrower substrate spectra. This was demonstrated in 2 previous studies in which DGGE was used to monitor population changes in enrichment cultures (Santegoeds et al. 1996, Jackson et al. 1998). In these studies it was concluded that the apparent differences in community composition could be attributed to the trade-off between numerical abundance in the original sample and the competitive ability of present populations to grow in the provided medium. However, dilution of inocula obtained from field samples may also result in lost species interactions because the activity of low abundant populations, which may be vital for high abundant populations, is lost in higher dilutions. A dilution procedure, therefore, may not recover the actual dominant field populations unless the exact conditions required for growth are provided.

Substrate spectra of the isolated Roseobacter relatives indicated that these strains grew particularly well on exudates of primary producers. Interestingly, several other studies have reported on the associations of Roseobacter-affiliated strains with primary producers. Bacterial symbionts from gall-bearing marine red algal species belonging to the genus Prionitis (Rhodophyta) were found to be affiliated to the genus Roseobacter (Ashen \& Goff 2000). Another isolate, Roseobacter algicola, was found to be associated to the phycosphere of a photosynthetic dinoflagellate (Lafay et al. 1995). Isolates of the Roseobacter group were found to be able to degrade the algal osmolyte dimethyl sulfoniopropionate (DMSP) and these bacteria accounted for $30 \%$ of the $16 \mathrm{~S}$ ribosomal DNA pool in coastal seawater of the southern United States (Gonzalez \& Moran 1997, Gonzalez et al. 1999). Although these reports are limited in number, they suggest that Roseobacter species play an important role in the mineralization of photosynthates in the marine environment because they are associated with primary producers.

In conclusion, we identified some numerically important populations of aerobic heterotrophic bacteria in a hypersaline microbial mat. Substrate spectra of Roseobacter-affiliated strains indicated that these bacteria were specialized in the degradation of photosynthates that are excreted by primary producers in the photic zone of the mat. Further investigations of Roseobacter-, Rhodobacter-, Marinobacter- and Halomonas-related populations in the carbon cycle in hypersaline mats using in situ techniques are underway. Only in situ techniques, such as a combination of microautoradiography and fluorescent in situ hybridization, can clarify whether these organisms are involved in their natural environment in the degradation of certain classes of organic compounds as their potential substrate spectra indicate.

Acknowledgements. We thank Yehuda Cohen for his hospitality and for providing access to the experimental ponds of the Interuniversity Institute of Eilat, Israel. We also wish to thank Niko Finke and Armin Gieseke for technical assistance, and Dirk de Beer and Tim Ferdelman for comments and helpful suggestions. This research was part of the Red Sea Program on Marine Sciences, financed by the German Ministry for research and development (BMBF).

\section{LITERATURE CITED}

Abed RMM, Garcia-Pichel F (2001) Long-term compositional changes after transplant in a microbial mat cyanobacterial community revealed using a polyphasic approach. Environ Microbiol 3(1):53-62

Albert DB, Martens CS (1997) Determination of low-molecular-weight organic acid concentrations in seawater and pore-water samples via HPLC. Mar Chem 56:27-37

Amann RI, Ludwig W, Schleifer KH (1995) Phylogenetic identification and in-situ detection of individual microbial-cells without cultivation. Microbiol Rev 59:143-169

Ashen JB, Goff LJ (2000) Molecular and ecological evidence for species specificity and coevolution in a group of marine algal-bacterial symbioses. Appl Environ Microbiol 66(7): 3024-3030

Bateson MM, Ward DM (1988) Photoexcretion and fate of glycolate in a hot-spring cyanobacterial mat. Appl Environ Microbiol 54(7):1738-1743

Bauld J (1984) Microbial mats in marginal marine environments: Shark Bay, Western Australia and Spencer Gulf, South Australia. In: Cohen Y, Castenholz RW, Halvorson HO (eds) Microbial mats: stromatolites. Alan R Liss, New York, p 39-58

Bradford MM (1976) A rapid and sensitive method for the quantification of microgram quantities of protein utilizing the principle of protein-dye binding. Anal Biochem 72: $248-254$

Caumette P, Cohen Y, Matheron R (1991) Isolation and characterization of Desulfovibrio halophilus sp nov, a halophilic sulfate-reducing bacterium isolated from Solar Lake (Sinai). Syst Appl Microbiol 14(1):33-38

DeWit R, Jonkers HM, VanDenEnde FP, VanGemerden H (1989) In situ fluctuations of oxygen and sulfide in marine microbial sediment ecosystems. Neth J Sea Res 23(3): 271-281

Galinski EA (1995) Osmoadaptation in bacteria. Adv Microb Physiol 37:273-328

Gonzalez JM, Moran MA (1997) Numerical dominance of a 
group of marine bacteria in the alpha-subclass of the class Proteobacteria in coastal seawater. Appl Environ Microbiol 63(11):4237-4242

Gonzalez JM, Kiene RP, Moran MA (1999) Transformation of sulfur compounds by an abundant lineage of marine bacteria in the alpha-subclass of the class Proteobacteria. Appl Environ Microbiol 65(9):3810-3819

Heijthuijsen J, Hansen TA (1986) Interspecies hydrogen transfer in co-cultures of methanol-utilizing acidogens and sulfate-reducing or methanogenic bacteria. FEMS Microbiol Ecol 38(1):57-64

Jackson CR, Roden EE, Churchill PF (1998) Changes in bacterial species composition in enrichment cultures with various dilutions of inoculum as monitored by denaturing gradient gel electrophoresis. Appl Environ Microbiol 64(12):5046-5048

Jørgensen BB, Cohen Y (1977) Solar Lake (Sinai). 5. The sulfur cycle of the benthic cyanobacterial mats. Limnol Oceanogr 22:657-666

Jørgensen BB, Revsbech NP, Cohen Y (1983) Photosynthesis and structure of benthic microbial mats-microelectrode and SEM studies of 4 cyanobacterial communities. Limnol Oceanogr 28(6):1075-1093

Krekeler D, Sigalevich P, Teske A, Cypionka H, Cohen Y (1997) A sulfate-reducing bacterium from the oxic layer of a microbial mat from Solar Lake (Sinai). Desulfovibrio oxyclinae sp nov. Arch Microbiol 167(6):369-375

Lafay B, Ruimy R, Detraubenberg CR, Breittmayer V, Gauthier MJ, Christen R (1995) Roseobacter algicola sp nov, a new marine bacterium isolated from the phycosphere of the toxin-producing dinoflagellate Prorocentrum lima. Int J Syst Bacteriol 45(2):290-296

Ludwig W, Strunk O, Klugbauer S, Klugbauer N, Weizenegger M, Neumaier J, Bachleiter M, Schleifer KH (1998) Bacterial phylogeny based on comparative sequence analysis. Electrophoresis 19:554-568

Minz D, Fishbain S, Green SJ, Muyzer G, Cohen Y, Rittmann BE, Stahl DA (1999a) Unexpected population distribution in a microbial mat community: sulfate-reducing bacteria localized to the highly oxic chemocline in contrast to a eukaryotic preference for anoxia. Appl Environ Microbiol 65(10):4659-4665

Minz D, Flax JL, Green SJ, Muyzer G, Cohen Y, Wagner M, Rittmann BE, Stahl DA (1999b) Diversity of sulfatereducing bacteria in oxic and anoxic regions of a microbial mat characterized by comparative analysis of dissimilatory sulfite reductase genes. Appl Environ Microbiol 65(10): $4666-4671$

Editorial responsibility: Gary King,

Walpole, Maine, USA
Muyzer G, Smalla K (1998) Application of denaturing gradient gel electrophoresis (DGGE) and temperature gradient gel electrophoresis (TGGE) in microbial ecology. Antonie Leeuwenhoek 73(1):127-141

Muyzer G, Dewaal EC, Uitterlinden AG (1993) Profiling of complex microbial populations by denaturing gradient gel electrophoresis analysis of polymerase chain reaction amplified genes coding for 16S ribosomal RNA. Appl Environ Microbiol 59(3):695-700

Muyzer G, Teske A, Wirsen CO, Jannasch HW (1995) Phylogenetic relationships of Thiomicrospira species and their identification in deep-sea hydrothermal vent samples by denaturing gradient gel electrophoresis of 16S rDNA fragments. Arch Microbiol 164(3):165-172

Pfennig N, Trüper HG (1992) The family Chromatiaceae. In: Balows A, Trüper HG, Dworkin M, Harder W, Schleifer $\mathrm{KH}$ (eds) The prokaryotes, 2nd edn. Springer-Verlag, New York, p 3200-3221

Santegoeds CM, Nold SC, Ward DM (1996) Denaturing gradient gel electrophoresis used to monitor the enrichment culture of aerobic chemoorganotrophic bacteria from a hot spring cyanobacterial mat. Appl Environ Microbiol 62(11): 3922-3928

Stal LJ (1995) Physiological ecology of cyanobacteria in microbial mats and other communities. New Phytol 131(1): $1-32$

Teiser MLO (1993) Extracellular low molecular weight organic compounds produced by Synechococcus sp. and their roles in the food web of alkaline hot spring microbial mat communities. PhD thesis, University of Oregon, Eugene

Teske A, Ramsing NB, Habicht K, Fukui M, Kuver J, Jørgensen BB, Cohen Y (1998) Sulfate-reducing bacteria and their activities in cyanobacterial mats of Solar Lake (Sinai, Egypt). Appl Environ Microbiol 64(8):2943-2951

VanGemerden H (1993) Microbial mats - a joint venture. Mar Geol 113(1-2):3-25

Wawer C, Muyzer G (1995) Genetic diversity of Desulfovibrio spp in environmental samples analyzed by denaturing gradient gel-electrophoresis of [Nife] hydrogenase gene fragments. Appl Environ Microbiol 61(6):2203-2210

Widdel F, Bak F (1992) Gram-negative mesophilic sulfatereducing bacteria. In: Balows A, Trüper HG, Dworkin M, Harder W, Schleifer KH (eds) The prokaryotes, 2nd edn. Springer-Verlag, New York, p 3353-3378

Wieland A, Kühl M (2000) Short-term temperature effects on oxygen and sulfide cycling in a hypersaline cyanobacterial mat (Solar Lake, Egypt). Mar Ecol Prog Ser 196:87-102

Submitted: April 10, 2002; Accepted: September 16, 2002

Proofs received from author(s): December 12, 2002 